\title{
Systemic Lupus Erythematosus: Immunologic Profile Associated to Clinical Manifestations in 30 Patients in the University Hospital of Cotonou, Benin
}

\begin{abstract}
Keywords: Connective tissue disease; Systemic lupus erythematosus: Antinuclear antibodies; Immuno-clinical association; Benin

\section{Summary}

Objective: The aims to describe the profile of antinuclea autoantibodies and their association with the clinical manifestations of Systemic Lupus Erythematosus (SLE).

Methods: A 15-year and 7-month retrospective, analytical, and multicenter study included patients fulfilling at least four of American College of Rheumatology criteria of SLE seen in Dermatology, Internal Medicine and Rheumatology Departments of two different hospitals in Cotonou.

Results: Thirty patients were recorded. The sex ratio M:F was 0.15 and the mean age was 33.1 years $+/-14.2$ years. Cutaneous $(26 / 30)$ and musculoskeletal $(23 / 30)$ lesions were predominant. Antinuclear antibodies were present in all patients. They were specific for antiDNA (22/30) anti-nucleosome (19/30), anti-Sm (18/30), anti-RNP (17/30) and anti-SSA (16/30). Anti-DNA antibodies were associated with musculoskeletal manifestations ( $p=0.02$ ); Anti-nucleosomes with malar rash $(p=0.01)$ and discoid lupus lesions ( $p=0.02)$; Anti-Sm and anti-RNP to kidney disorders ( $p \leq 0.02)$, anti-SSA to malar rash ( $p=0.05)$ and haematologic signs $(p=0.03)$
\end{abstract}

Conclusion: Some immuno-clinical correlations of SLE on dark skin have been confirmed and others have been highlighted. This reflects the intricacy of environmental and genetic factors that underlie interracial and intra-racial differences.

\section{Introduction}

Systemic Lupus Erythematosus (SLE) is an auto-immune systemic disease that is no specific to an organ that progresses in relapses. This is the most common form of connective tissue disease characterized by protean clinical manifestations and antinuclear antibodies (ANA) production $[1,2]$.

The physiopathology of SLE remains poorly elucidated despite a notable advance in the knowledge of the pathogenic mechanisms of antibodies involved in the occurrence of tissue lesions. These antinuclear antibodies are often present several years before the clinical start of the disease: 78\% for anti-nuclear antibodies, 55\% for anti-DNA, 55\% for anti-SSA, 34\% for anti-Sm, 26\% for anti-U1 RNP (ELISA) $[3,4]$.

Some clinical and biological features have been studied in black subjects [5-12]. In African context, very few studies have attempted to establish the predictive value of immunological parameters in the onset and evolution of clinical manifestations.

\section{Journal of}

\section{Clinical \& Investigative} Dermatology

\author{
Dégboé $\mathrm{B}^{{ }^{*}}$, Atadokpede $\mathrm{F}^{1}$, Adégbidi $\mathrm{H}^{1}$, Sémikenké \\ Kazoza $S^{1}$, Agbodandé $A^{2}$, Zomaletho $Z^{3}$, Koudoukpo \\ $\mathrm{C}^{4}$ and do Ango-Padonou $\mathrm{F}^{1}$ \\ ${ }^{\prime}$ Department of Dermatology-Venerology, Faculty of Health Sciences, \\ University of Abomey-Calavi, Cotonou, Benin \\ ${ }^{2}$ Departement of Internal Medecine, Faculty of Health Sciences, University \\ of Abomey-Calavi, Cotonou, Benin \\ ${ }^{3}$ Departement of Rheumatology, Faculty of Health Sciences, University of \\ Abomey-Calavi, Cotonou, Benin \\ ${ }^{4}$ Department of Dermatology-Venerology, Faculty of Medecine, University \\ of Parakou, Parakou, Benin \\ *Address for Correspondence \\ Bérénice Degboe, Department of Dermatology-Venerology, Faculty \\ of Health Sciences, University of Abomey-Calavi, Cotonou, Box \\ 266 Godomey, Benin, Tel: (00229) 96960005/ 95497341; E-mail: \\ kebdegboe@yahoo.fr \\ Submission: 29 March, 2017 \\ Accepted: 26 May, 2017 \\ Published: 02 June, 2017 \\ Copyright: (c) 2017 Dégboé B, et al. This is an open access article \\ distributed under the Creative Commons Attribution License, which permits \\ unrestricted use, distribution, and reproduction in any medium, provided the \\ original work is properly cited.
}

The objective of our study was to describe the profile of antinuclear antibodies and their association with clinical manifestations during SLE in two hospitals in Cotonou, Republic of Benin.

\section{Methods}

A multi-centric study was carried out jointly in the DermatologyVenerology, Rheumatology and Internal Medicine departments of National University Hospital Hubert Koutoukou Maga and in the Department of Dermatology-Venerology of the Military Hospital (HIA) both in Cotonou. This was a transversal, retrospective and analytical study that took place from $1^{\text {st }}$ January 2000 to $31^{\text {st }}$ July 2015 (15 years 7 months). All cases of SLE (exhaustive sampling) seen in the above-mentioned departments during the study period who had at least four clinico-biological criteria of the American College of Rheumatology (ACR) [13] and done minimal immunologic investigation in the CERBA laboratory (France) were included. Minimal immunologic investigations was including at least antinuclear antibodies, anti-DNA antibodies and anti-soluble nuclear antigen antibodies, namely anti Sm, anti RNP, anti SSA and anti-SSB.

Cases of Mixed Connective Tissue Disease (MCTD), induced lupus and incomplete records were not included. MCTD is a clinico-biological entity isolated by Sharp that contains a variable proportion of signs of lupus, scleroderma, dermato-polymyositis and rheumatoid arthritis. Induced lupus account for about $10 \%$ of systemic lupus. It is caused by inducer drugs. They are characterized by a high level of ANA contrasting with the usual absence of DNA and hypocomplementemia [14].

Epidemiological, clinical and immunologic characteristics of the patients were recorded using a fact sheet. The determination of ANA 
Citation: Dégboé B, Atadokpede F, Adégbidi H, Kazoza SS, Agbodandé A, et al. Systemic Lupus Erythematosus: Immunologic Profile According to Clinical Manifestations in 30 Patients in the University Hospital of Cotonou, Benin. J Clin Investigat Dermatol. 2017;5(1): 6.

response levels was made by indirect immuno-fluorescence technique using human laryngeal carcinoma cells as substrate. The results were interpreted according to the appearance of localized fluorescence at the nucleus or cytoplasm of the substrate cells. The ANA positivity threshold was $80 \mathrm{IU}$ and the rate was classified as high above $320 \mathrm{IU}$. ELISA technique was used for the detection of anti-DNA antibodies and anti-soluble nuclear antigen antibodies, namely anti Sm, anti RNP, anti SSA and anti-SSB.

The data were analyzed using EPI-info 3.5.1. The quantitative variables were described with their mean and standard deviation, the qualitative variables with the proportions. The association between the immunologic profile and the other independent variables under study was made by a bivariate analysis using Pearson Chi-square and Fisher's exact test when the numbers were less than 5 . The results were significant when $\mathrm{p}<0.05$.

The local ethics committee gave a favorable opinion. The information was confidential and anonymous.

\section{Results}

Sixty-one cases of SLE were recorded, meaning a frequency of 3.9 cases per year. Our population was dark skinned. Among these 61 patients, 30 had minimal immunological investigation. The sex-ratio $\mathrm{M}: \mathrm{F}$ in this subpopulation was 0.15 (4 men and 26 women). The mean age of our patients was 33.1 years \pm 14.2 years with extremes of 9 years and 58 years. The highest frequency was 16-24 years.

Indicative signs of SLE are listed in Table 1. Musculoskeletal and skin disorders were the main signs isolated or associated with other signs. The mean time between the onset of the developmental signs and the consultation was $29.2 \pm 39.6$ months with extremes of 1 and 144 months.

Table 2 summarizes the different clinical manifestations found during the examination of the 30 patients.

Skin disorders occurred in the form of discoid lupus (14/30), malar rash (10/30) alopecia (6/30), vascular purpura (2/30). There were no cases of photosensitivity.

Arthralgias without arthritis (21/30), arthritis (6/30), not true arthitis, diffuse myalgia $(8 / 30)$ and synovitis (3/30) represented rheumatologic disorders.

Renal impairment included lupus glomerulonephritis (3/30) and renal insufficiency (2/30). Haematologic lesions (4/30) were made of nodes not poly-adenopathies in 3 patients, clinical anemia in 2 patients

Table 1: Distribution related to lupus signs motivate Reasons for consultations in our 30 patients from 2000 to 2015 in University Hospitals of Cotonou (Benin).

\begin{tabular}{|c|c|c|}
\hline Symptoms & Number & Fréquency (\%) \\
\hline Musculoskeletal & $19 / 30$ & 63.3 \\
\hline Cutaneous & $9 / 30$ & 30.0 \\
\hline Cutaneous and long term fever & $7 / 30$ & 23.3 \\
\hline Musculoskeletal and long term fever & $5 / 30$ & 16.7 \\
\hline Long term fever & $3 / 30$ & 10 \\
\hline Musculoskeletal and renal & $2 / 30$ & 6.7 \\
\hline Cutaneous and renal & $1 / 30$ & 3.3 \\
\hline
\end{tabular}

Table 2: Distribution related to Clinical manifestations at presentation in 30 patients from 2000 to 2015 in the University Hospitals of Cotonou (Benin).

\begin{tabular}{|c|c|c|}
\hline Clinical manifestations & Number & Frequency (\%) \\
\hline Cutaneous & $26 / 30$ & 86.7 \\
\hline Musculoskeletal & $23 / 30$ & 76.7 \\
\hline Renal & $4 / 30$ & 13.3 \\
\hline Haematologic & $4 / 30$ & 13.3 \\
\hline Cardiac & $4 / 30$ & 13.3 \\
\hline Pleuro-pulmonary & $3 / 30$ & 10 \\
\hline Psychiatric & $2 / 30$ & 6.7 \\
\hline Neurologic & $1 / 30$ & 3.3 \\
\hline & & \\
\hline & & $B .3$ \\
\hline
\end{tabular}

Table 3: Qualitative abnormalities of immunologic disorders in 30 SLE patients from 2000 to 2015 in Cotonou (Benin).

\begin{tabular}{|c|c|c|c|c|}
\hline \multirow{2}{*}{ Immunologic markers } & \multicolumn{2}{|c|}{$\begin{array}{c}\text { Present } \\
\text { Number (\%) }\end{array}$} & \multicolumn{2}{c|}{$\begin{array}{c}\text { Absent } \\
\text { Number (\%) }\end{array}$} \\
\hline Antibodies anti-nuclear & $30 / 30$ & $(100)$ & $00 / 30$ & $(00)$ \\
\hline Antibodies anti-DNA & $22 / 30$ & $(73.3)$ & $08 / 30$ & $(26.7)$ \\
\hline Antibodies anti-nucleosome & $19 / 30$ & $(63.3)$ & $11 / 30$ & $(36.7)$ \\
\hline Antibodies anti-Sm & $18 / 30$ & $(60.0)$ & $12 / 30$ & $(40.0)$ \\
\hline Antibodies anti-RNP & $17 / 30$ & $(56.7)$ & $13 / 30$ & $(43.3)$ \\
\hline Antibodies anti-SSA & $16 / 30$ & $(53.3)$ & $14 / 30$ & $(46.7)$ \\
\hline Antibodies anti-SSB & $05 / 30$ & $(16.7)$ & $25 / 30$ & $(83.3)$ \\
\hline
\end{tabular}

and splenomegaly in 1 patient. Cardiac injury was dominated by isolated pericarditis (3/30). Pulmonary manifestations were pleurisy (2/30) and pulmonary arterial hypertension (PAH). Anxio-depressive syndrome $(2 / 30)$ was the psychiatric manifestation. Cerebrovascular accident was the neurological manifestation observed in one patient. No patient was seen with digestive manifestations in our study.

No-specific biological signs were an acceleration of the erythrocyte sedimentation rate (20/30), anemia (17/30), leucopenia $(12 / 30)$, lymphopenia (8/30), thrombocytopenia 8/30), C-Reactive Protein positive (6/30), hyper-gammaglobulinemia (5/30) and hypoalbuminemia (3/30). The qualitative immunologic profile of the 30 patients is shown in Table 3. Some of these ANA were significantly or not associated with specific clinical manifestations. This is illustrated in Table 4.

Anti-DNA antibodies were present in the major clinical manifestations in varying proportions. However, their presence was significantly associated with musculoskeletal disorders ( $\mathrm{p}=$ 0.02). Malar rash and discoid lupus lesions were characterized by a significant production of anti-nucleosome, anti-SSA and anti-RNP antibodies and in a small proportion (20\% and $35.7 \%$ respectively) of the anti-Sm antibodies. Anti-SSA antibodies were found significantly in the onset of malar rash $(p=0.05)$. The production of anti-nucleosome antibodies accompanied these two types of dermatological manifestations with a significant association ( $\mathrm{p} \leq$ $0.02)$.

Renal involvement was characterized by absence of antinucleosome and anti-SSA antibodies, whereas they were significantly related to important production of anti-Sm and anti-RNP antibodies 
Citation: Dégboé B, Atadokpede F, Adégbidi H, Kazoza SS, Agbodandé A, et al. Systemic Lupus Erythematosus: Immunologic Profile According to Clinical Manifestations in 30 Patients in the University Hospital of Cotonou, Benin. J Clin Investigat Dermatol. 2017;5(1): 6.

Table 4: Profile of the main antinuclear antibodies associated with the clinical manifestations of SLE in our 30 patients from 2000 to 2015 in Cotonou, Benin.

\begin{tabular}{|c|c|c|c|c|c|}
\hline \multicolumn{6}{|c|}{ Immunologic profile $\%\left(^{*}\right)$} \\
\hline $\begin{array}{c}\text { Clinical } \\
\text { manifestations }\end{array}$ & $\begin{array}{c}\text { Anti DNA } \\
\text { (p) }\end{array}$ & $\begin{array}{c}\text { Anti } \\
\text { nucleosomes } \\
\text { (p) }\end{array}$ & $\begin{array}{c}\text { Anti Sm } \\
(p)\end{array}$ & $\begin{array}{c}\text { Anti RNP } \\
(p)\end{array}$ & $\begin{array}{c}\text { Anti SSA } \\
(p)\end{array}$ \\
\hline $\begin{array}{c}\text { Malar rash } \\
n=10\end{array}$ & 70 (ns) & $70(0.01)$ & 20 (ns) & $100(\mathrm{~ns})$ & $90(0.05)$ \\
\hline $\begin{array}{l}\text { Discoid lupus } \\
n=14\end{array}$ & 64.3 (ns) & $71.4(0.02)$ & $\begin{array}{l}35.7 \\
\text { (ns) }\end{array}$ & $78.6(\mathrm{~ns})$ & 71.4 (ns) \\
\hline $\begin{array}{c}\text { Musculoskeletal } \\
n=23\end{array}$ & $\begin{array}{c}100 \\
(0.02)\end{array}$ & $8.7(\mathrm{~ns})$ & $\begin{array}{l}52.2 \\
\text { (ns) }\end{array}$ & 65.2(ns) & 65.2 (ns) \\
\hline $\begin{array}{l}\text { Renal } \\
n=4\end{array}$ & 75 (ns) & 00 (ns) & $\begin{array}{c}75 \\
(0.02)\end{array}$ & $\begin{array}{c}100 \\
(0.02)\end{array}$ & $00(\mathrm{~ns})$ \\
\hline $\begin{array}{c}\text { Haematologic } \\
n=4\end{array}$ & 100 (ns) & 50 (ns) & 00 (ns) & 00 (ns) & $\begin{array}{c}100 \\
(0.03)\end{array}$ \\
\hline
\end{tabular}

(*): Proportion related to seropositivity to antinuclear antibody to the number of patients presenting each type of clinical manifestations. Example of malar rash: 7 positive cases to anti-DNA antibodies on 10 patients presenting malar rash = $70 \%$

ns: when $p>0.05$

$(\mathrm{p} \leq 0.02)$.

Haematologic damage was significantly associated with the production of anti-SSA antibodies $(\mathrm{p}=0.03)$. Anti Sm and anti RNP were completely absent.

\section{Discussion}

The limitations of our study were linked, on the one hand, to its retrospective character, which did not allow us to have as much information as possible. On the other hand, the data collection concerned only patients seen respectively in the DermatologyVenerology departments at the Military Hospital and National University Hospital of Cotonou and in the Rheumatology and Internal Medicine departments of National University Hospital of Cotonou. These two hospitals, although are referral centers, do not receive all the cases of SLE since some patients consult in peripheral health centers for economic and geographic accessibility or cultural reasons. That's why the results do not necessarily reflect the frequency and prevalence of this pathology in Cotonou. Notwithstanding these limitations, we were able to make a meaningful analysis of the results in order to draw conclusions related to the objectives.

The recruitment was multicentric and multidisciplinary. In our series the signs were dominated by musculoskeletal and skin affections isolated or associated with other clinical manifestations. The functional discomfort caused by musculoskeletal disorders and the displaying character of skin disorders on black skin could motivate the patients to consult frequently.

Long-term fever was observed in 8 patients. In tropical areas, where many infections such as malaria, typhoid fever, tuberculosis may lead to more diagnostic, the incidence of SLE is further underestimated.

The clinical polymorphism observed was in accordance with that reported in the literature [1,2,5-12,15-21]. This polymorphism, coupled with the limited accessibility of the immunoassay (performed in only $30-50 \%$ of patients), makes the clinical diagnosis of SLE even

Table 5: Comparative studies of clinical and biological manifestations of SLE in our 30 patients with data from the subregion [5-10,13]

\begin{tabular}{|c|c|c|c|c|c|c|c|c|}
\hline $\begin{array}{l}\text { Clinical and biological } \\
\text { manifestations }\end{array}$ & $\begin{array}{c}\text { Benin } \\
\mathrm{n}=30\end{array}$ & $\begin{array}{c}\text { IvoryCoast } \\
n=117\end{array}$ & $\begin{array}{c}\text { Senegal } \\
n=142\end{array}$ & $\begin{array}{c}\text { Nigeria } \\
n=66\end{array}$ & $\begin{array}{c}\text { Cameroon } \\
n=39\end{array}$ & $\begin{array}{c}\text { Gabon } \\
n=37\end{array}$ & $\begin{array}{l}\text { South Africa } \\
n=40\end{array}$ & $\begin{array}{c}\text { Tunisia } \\
n=146\end{array}$ \\
\hline Cutaneous & 86.7 & 71.8 & 90.8 & - & 55.4 & 62.1 & - & 75.3 \\
\hline Malar rash & 33.3 & 43.6 & 43 & 21.2 & 15.4 & - & 59 & 52 \\
\hline Discoid lupus & 46.7 & 14.5 & 27.5 & 43.9 & 5.1 & - & 52 & 9.6 \\
\hline Photosensibility & - & 41.9 & 57.7 & 9 & 7.7 & - & 52 & 47.3 \\
\hline Alopecias & 20 & 31.6 & - & 45 & 20.5 & - & 13 & 21.2 \\
\hline Musculoskeletal & 76.7 & 86.3 & 68.3 & 87 & 64.1 & 59.4 & 72 & 84.2 \\
\hline Renal & 13.3 & 40.2 & 49.3 & - & 17.9 & 16.2 & 58 & 59 \\
\hline Neurologic & 3.3 & 36.7 & 17.6 & - & 10.3 & 24.3 & 18 & 18.5 \\
\hline Hematologic & - & - & - & 47 & - & - & 40 & 87 \\
\hline Anemia & 56.7 & 86.3 & 49.2 & - & 72 & - & 5 & 78.7 \\
\hline Leucopenia & 40 & 15.4 & 19.7 & - & 56 & - & 32 & 48 \\
\hline Lymphopenia & 26.7 & - & 14.8 & - & 44 & - & 10 & 47.3 \\
\hline Thrombopenia & 26.7 & 13.7 & 13.4 & - & 16 & - & & 24.7 \\
\hline ANA & 100 & 94.1 & 97.9 & 98.5 & 86.1 & 100 & 100 & 97.3 \\
\hline Anti DNA & 73.3 & 73.5 & 45.7 & 53.8 & 73.5 & 63.8 & 30 & 69.2 \\
\hline Anti Sm & 60 & 75 & 65.2 & 63.6 & - & 33.3 & 67 & 39.2 \\
\hline Anti- nucleosomes & 63.3 & - & - & - & - & - & - & 62.3 \\
\hline Anti- SSA & 53.3 & 75 & - & 46.7 & - & - & 68 & 58 \\
\hline Anti SSB & 16.7 & 56.2 & - & 9 & - & - & 30 & 22 \\
\hline Anti RNP & 56.7 & 100 & - & 66.7 & - & - & 75 & 39.2 \\
\hline
\end{tabular}


Citation: Dégboé B, Atadokpede F, Adégbidi H, Kazoza SS, Agbodandé A, et al. Systemic Lupus Erythematosus: Immunologic Profile According to Clinical Manifestations in 30 Patients in the University Hospital of Cotonou, Benin. J Clin Investigat Dermatol. 2017;5(1): 6.

Table 6: Immunologic profile associated to some main clinical manifestations according to some authors.

\begin{tabular}{|c|c|c|}
\hline Associations & Studies & $p-$ \\
value
\end{tabular}

more difficult for untrained practitioners in black Africa. Indeed, the immunological assessment is sent abroad for analysis and its cost is often beyond the reach of patients [5-9].

Skin and musculoskeletal disorders were the most frequent clinical manifestations during the examination. Our results are similar to those in the sub-region [5-10,15-18] and confirm the predominance of benign cutaneous-musculoskeletal forms (Table 6) classically opposed to the severe visceral forms more frequently reported in Western countries among blacks and Caucasians $[1,2,11,12,20]$. They may be severe under-diagnosed cases or severe cases that die before coming to hospital or severe cases may be treated outside the referral centers in black Africa.

The main cutaneous lesions in our series were discoid lupus (14/30 cases), malar rash (10/30 cases) and alopecia (6/30). Previous studies comparing the characteristics of SLE in Caucasians and Negroes showed that discoid lupus is more common in blacks in all regions than in Caucasians, whereas malar rash and photosensitivity are more frequent in Caucasians in a statistically significant way $[1,10-12,20]$. In Senegal and Ivory Coast, malar rash is the most frequent cutaneous manifestations found in nearly half of the patients [5,6]. In North Africa, the profile of cutaneous manifestations is similar to that of Westerners, dominated by malar rash and photosensitivity [15-18].

In terms of alopecia frequency, our results are similar to those of other countries in the sub-region (Table 5) except Nigeria and Cameroon, where it is the most common cutaneous manifestation [5-10]. The photosensitivity was not found in our series. A small proportion was observed in Nigeria and Cameroon [7,8]. Previous studies of the particularities of SLE have generally reported a low incidence of photosensitivity on black skin, which is related to the protective role of the phototype against ultraviolet rays $[11,12]$. However, in Ivory Coast, Senegal, South and North Africa, a high proportion of photosensitivity has been reported [5,6,10,15-18]. We suggest interplay of environmental and genetic influences that could explain these intra-racial differences.
Renal manifestations, dominated by glomerular disease, are the second leading cause of death after infectious complications in patients with SLE. They are reported to be more frequent in lupus patients of African descent [11,12], and also in cases of infantile lupus and in male $[2,20,22]$. Its frequency, appreciated by the existence of a frank proteinuria varies according to the series between 40 and $60 \%$. But renal biopsy shows that the anatomical frequency is higher, 70 to $80 \%[1,4]$. Lupus nephritis were noted in a small proportion $(4 / 30)$ in our series. These results are superimposed on those obtained in Gabon and Cameroon (Table 5), but significantly lower than those of other countries in the sub-region. [5-10,15-17]. In Benin, we have no possibility of carrying out the renal biopsy. This may contribute to underestimating the actual frequency of renal disease in our series.

According to the literature, ANA constitute the quasi-constant immunological markers of SLE with a frequency varying between 85 and $100 \%$. The most specific of the SLE are the antibodies antiDNA, anti-Sm, anti-nucleosomes and anti-protein $\mathrm{P}$ ribosome. In the immunopathogenesis of lupus disease, these variations may result from epitopic dissemination leading to the release of cryptic epitopes by auto-antibodies and promoting clinical diversity $[1,4,23]$. In our study, ANA was positive in all patients. They were mainly anti-DNA, anti-nucleosomes, anti-Sm, anti-RNP, anti-SSA antibodies present in at least half of the patients.

As shown in some previous studies $[9,11,15,17,20]$, anti-DNA antibodies were the most frequent in our series. In other countries of the sub-region, they were second rank after anti-Sm antibodies [5-8]. This difference in results can be explained by the variability of sensitivity due to the technical methods of antibody detection.

Anti-DNA antibodies are the most specific immunologic marker for SLE with anti-Sm antibodies. Their rate would be correlated with the activity of the disease and the risk of renal disease $[1,3,5,16,20]$. Unlike these studies, we did not find a significant association with kidney disorders. The same finding was made by Skare in a Brazilian cohort of 228 patients [24]. In our study, they were present whatever the clinical manifestations in a proportion ranging between 64.3$100 \%$ (Table 4). However, we found their association significantly with musculoskeletal disorders $(\mathrm{p}=0.02)$. Diallo and al in Senegal, Haddouk and al and Ghedira in Tunisia observed the same association $[16,17,23]$

Anti-nucleosome antibodies are the most sensitive markers of SLE, present even in forms without anti-DNA antibodies $[1,3,25]$. They were significantly associated with cutaneous lesions such as malar rash and discoid lupus lesions ( $\mathrm{p} \leq 0.02)$. They were found in one patient in two with haematologic impairment a low proportion in musculoskeletal disorders and absent in patients with kidney problems. Data on the prognostic value of anti-nucleosome antibodies, particularly in the case of lupus nephritis, are contradictory [25]. Classes of anti-nucleosome IgG antibodies have been detected in patients without renal impairment, whereas Ig G3 are associated with lupus nephropathy [25].

The anti-Sm antibodies found in $60 \%$ of our patients confirm a finding frequently reported in studies in black patients with rates ranging between $30 \%$ and $75 \%[5-9,12]$, compared to Caucasian populations which show the prevalence of these auto-antibodies 
Citation: Dégboé B, Atadokpede F, Adégbidi H, Kazoza SS, Agbodandé A, et al. Systemic Lupus Erythematosus: Immunologic Profile According to Clinical Manifestations in 30 Patients in the University Hospital of Cotonou, Benin. J Clin Investigat Dermatol. 2017;5(1): 6.

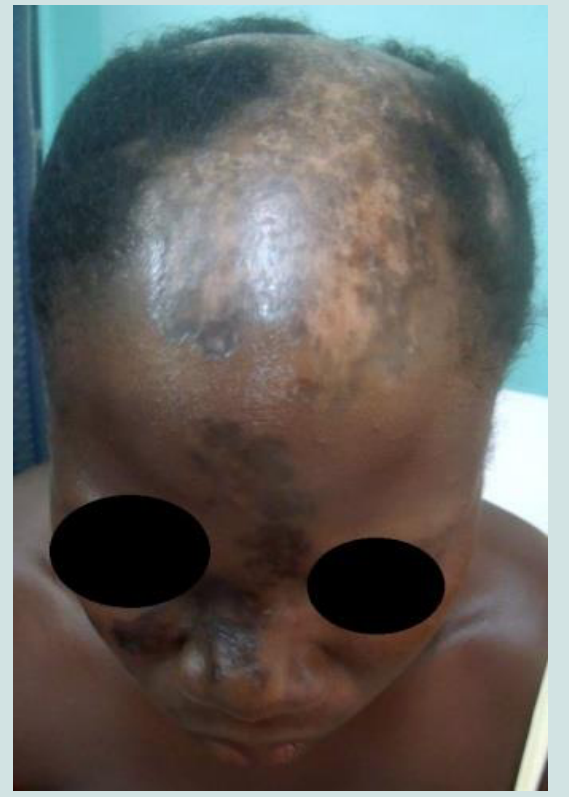

Figure 1: Discoîd lupus.

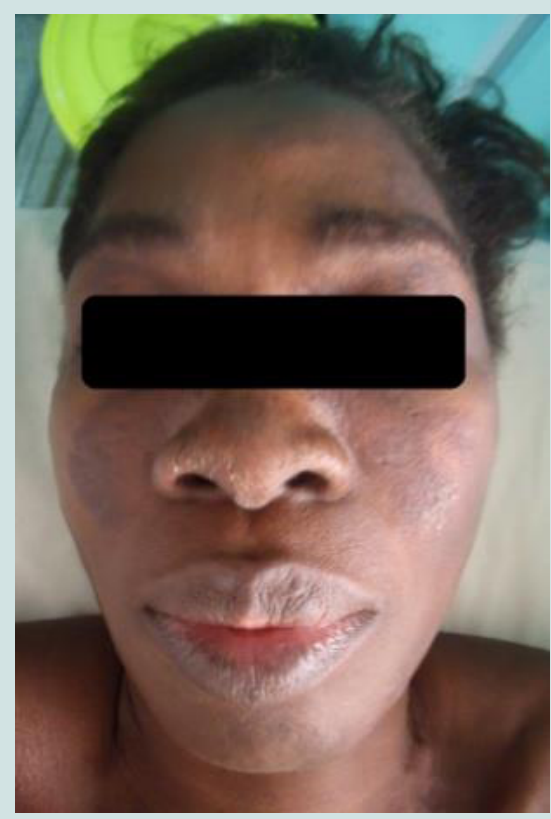

Figure 2: Malar rash.

in only 10 to $20 \%$ of patients $[1,10,11,20]$. We found a significant correlation with kidney disorders $(\mathrm{p}=0.018)$. A study related to black women with lupus nephritis found their presence in $63 \%$ of patients [26] in the United States of America.

In the case of anti-RNP, $56.7 \%$ of patients were positive. This result is consistent with previous studies in the sub-region [5,9]. As Yamamoto and al in a Franco-Brazilian cohort, we found a correlation at significant levels $(\mathrm{p}=0.02)$ with kidney disorders [27].

In addition, a parallelism between the frequency of anti-Sm and anti RNP antibodies reported by some authors [5-9,27] has been confirmed in our series. This is because lupus patients who strongly respond to the Sm antigen also have amplitudes of high anti-RNP responses. These two auto-antigens are ribo-nucleoproteins therefore coming from the same nuclear structure $[3,23]$.

In addition, to the positive correlation between these two antibodies, their association was significantly accompanied kidney disorders ( $\mathrm{p} \leq 0.02$ ) whereas they were totally absent in haematologic manifestations (Table 4). The same association was described by $\mathrm{Iba} \mathrm{Ba}$ and $\mathrm{al}$ in Gabon and found in more than half of a series in black women with lupus nephritis in the United States $[9,26]$. The association of anti-Sm and anti-RNP antibodies could also be a particularity of SLE with risk of renal disease on black skin. Auto-antibodies can carry out their pathogenic effects by several mechanisms. Apart from anti-SSA antibodies, they generally have no direct action on the tissue. Direct binding of anti-SSA antibodies to keratinocyte antigens induces cell death and is the cause of skin lesions [3]. The high frequency of these antibodies during SLE has been described by some authors in the sub-region [5,7,10,15-17]. They were significantly present in haematologic $(\mathrm{p}=0.03)$ and malar rash $(\mathrm{p}=0.05)$, and not significantly in discoid lupus and musculoskeletal disorders. Ghédira and al in Tunisia and Tickly and al in South Africa reported a significant association between anti-SSA antibodies and malar rash $[17,28]$. Diango Ndiaye and al in Senegal found their association with musculoskeletal manifestations [29].

Associated with anti-nucleosome antibodies, anti-SSA antibodies may constitute the antibodies characteristic of relatively benign forms of SLE, such as cutaneous, haematologic and musculoskeletal signs. Otherwise, the association of these two antibodies was completely absent in the lupus nephritis of our series.

Recent evidence, however, contradicts the absolute benignity of cutaneous forms. Two recent studies in large series in Brazil and the United States have shown that discoid lupus is associated with mild disease progression whereas malar rash is predictive of severe SLE $[24,30]$.

In our study, while the presence of anti-Sm and anti RNP antibodies excluded haematologic symptoms for a significant correlation with lupus nephritis, the reverse was observed with the combination of anti-nucleosome and anti-SSA antibodies. A study on a large series will allow us to confirm or reverse this finding and to better define the specific immunologic profile associated with lupus including both renal and haematologic manifestations.

\section{Conclusion}

The clinico-biological polymorphism of SLE was confirmed in our study.

Benign musculoskeletal and cutaneous disorders were the main clinical manifestations of SLE patients in hospitals in Cotonou. Some immuno-clinical correlations of SLE on black skin have been confirmed and others have been highlighted. This reflects the intricacy of environmental and genetic factors that underlie interracial and intra-racial differences. The investigations are therefore to be pursued for a better knowledge of the physiopathology of SLE which can lead to pathways of therapeutic research. 
Citation: Dégboé B, Atadokpede F, Adégbidi H, Kazoza SS, Agbodandé A, et al. Systemic Lupus Erythematosus: Immunologic Profile According to Clinical Manifestations in 30 Patients in the University Hospital of Cotonou, Benin. J Clin Investigat Dermatol. 2017;5(1): 6.

\section{References}

1. Meyer O (2005) Systemic lupus erythematosus. EMC-Rhumatologie Orthopédie 2: 1-32.

2. Laurent A, Alexis M, Zahir A (2011) Manifestations cliniques et biologiques du lupus systémique. Revue du praticien 61: 1254-1258.

3. Guillaud C, Hüe S, Igen-Housz-Oro S (2013) ANA: What the dermatologist should know, Antinuclear antibodies: What dermatologists need to know. Ann Dermatol Venereol 140: 821-826.

4. Mathiana A, Arnauda L, Amouraa Z (2014) Physiopathologie du lupus systémique : le point en 2014. Rev Med Int 35: 503-511.

5. Gbané-Koné M, Ouattara B, Mermoz Djaha KJ, Megne E, Ngandeu AN, et al. (2015) Autoantibodies in systemic lupus erythematosus, in black African subject, in Abidjan. J Rheumatol Autoimmune Dis 5: 28-35.

6. Fall S, Pouye A, Ndiaye FS, Ndongo S, Leye Y, et al. (2011) Initial presentation of systemic lupus erythematosus in Senegal. Med Black Africa 58: 156-160.

7. Adelowo OO, Oguntona SA (2009) Pattern of systemic lupus erythematosus among Nigerians. Clin Rheumatol 28: 699-703.

8. Bija MD, Luma Namme H, Ashuntantang G, Epée H, Kemta F, et al. (2014 Clinical presentation, treatment and outcome of patients with systemic lupus erythematosus seen at a rheumatology clinic in Douala, Cameroon. Health Sci Dis 15: 1-5.

9. Iba BJ, Nzenze JR, Biteghe B, Missounga L, Bignoumba Ibouili R, et al (2011) Clinical, biological and evolutionary profile of systemic lupus in hospitals. Medicine of Black Africa 58: 551-559.

10. Jacyk WK, Steenkamp KJ (1996) Systemic lupus erythematosus in South African blacks: Prospective study. Int J Dermatol 35: 707-710.

11. Molina JF, Molina J, Garcia C, Gharavi AE, Wilson WA, et al. (1997) Ethnic differences in the clinical expression of systemic lupus erythematosus: A comparative study between African-American and Latin American. Lupus 6 : 63-67.

12. Meyer O (2002) Systemic lupus in non-Caucasians. Rev Rhum 69: 801-808

13. Hochberg MC (1997) Updating the American college of rheumatology revised criteria for the classification of systemic lupus erythematosus. Arthritis Rheum 40: 1725.

14. Lipsker D, Saurat JH. Signs of lupus erythematosus in dermatology and sexually transmitted infections, ( $5^{\text {th }}$ edn). Elsevier Masson, pp. 346-356.

15. Jallouli M, Frigui M, Ben Hmida M, Marzouk S, Kaddour N, et al. (2008) Clinical and immunological manifestations of systemic lupus erythematosus: Study on 146 south Tunisian patients. Saudi J Kidney Dis Transpl 19: 1001 1008

16. Haddouk S, Ben Ayed M, Baklouti S, Hachicha J, Bahloul Z, et al. (2005) Autoantibodies in systemic lupus erythematosus: profile and clinical correlations. Pathol Biol 53: 311-317.
17. Ghedira I, Sakly W, Jeddi M (2002) Clinical and serological characteristics of systemic lupus erythematosus: 128 cases. Pathol Biol (Paris) 50: 18-24.

18. Bouras M, Hali F, Khadir K, Benchikhi H (2014) Systemic lupus erythematosus: mortality and poor prognostic factors in a Moroccan series of 129 cases. Ann Dermatol Venereol 141: 141-143.

19. Bae SC, Fraser P, Liang MH (1998) The epidemiology of systemic lupus erythematosus in populations of African ancestry: A critical review of the "prevalence gradient hypothesis". Arthritis Rheum 41: 2091-2099.

20. Cervera R, Khamashta MA, Font J, Sebastiani GD, Gil A, et al. (1993) Systemic lupus erythematosus: Clinical and immunological patterns of disease expression in a cohort of 1,000 patients. The European Working Party on Systemic Lupus Erythematosus. Medicine (Baltimore) 72: 113-124.

21. Zomalheto $Z$, Assogba $M$, Agbodandé $A$, Atadokpèdé $F$, Gounongbé $M$, et al. (2014) Pattern of systemic lupus erythematosus in Benin and West African patients. Tunis Med 92: 707-710.

22. Ambrose N, Morgan TA, Galloway J, lonnoau Y, Beresford MW, et al. (2016) Differences in disease phenotype and severity in SLE across age groups. Lupus 25: 1542-1550.

23. Diallo MS, Mbengue B, Seck A, Cheikh Ndao A, Sylla Niang M, et al. (2014) Profile of autoantibody responses by age and clinical symptomatology in patients with lupus erythematosus. Ann Clin Biol 72: 351-358.

24. Thelma Larocca S, Barbara S, Emilio W, Diogo DF (2013) Prognosis of patients with systemic lupus erythematosus and discoid lesions. An Bras Dermatol 88: 755-758.

25. Lepers S, Hachulla E, Leleux E, Hatron PY, Prin L, et al. (2002) Relevance of anti-nucleosome antibodies detected by enzyme-based immunoassays in lupus diagnosis. Comparative analysis of four commercial kits Pathol Biol (Paris) 50: 584-590

26. McCarty GA, Harley JB, Reichlin M (1993) A distinctive autoantibody profile in black female patients with lupus nephritis. Arthritis Rheum 36: 1560-1565.

27. Yamamoto AM, Amoura Z, Johannet C, Jeronimo AL, Campos H, et al. (2000) Quantitative radioligand assays using de novo-synthesized recombinan autoantigens in connective tissue diseases: New tools to approach the pathogenic significance of anti-RNP antibodies in rheumatic diseases. Arthritis Rheum 43: 689-698.

28. Tickly M, Burgin S, Mohanlal P, Bellingan A, George J (1996) Autoantibodies in black South Africans with systemic lupus erythematosus: spectrum and clinical associations. Clin Rheumatol 15: 261-265.

29. Ndiaye FS, Ka MM, Fall S, Dioum A, Pouye A, et al. (2011) Hematologic and immunologic signs of lupus: the experience of the hospital of Dakar. Sante 21: $143-148$.

30. Drucker AM, Su J, Mussani F, Siddha SK, Gladman DD, et al. (2016) Prognostic implications of active discoid lupus erythematosus and malar rash at the time of diagnosis of systemic lupus erythematosus: Results from a prospective cohort study. Lupus 25: 376-381. 